\title{
The Fate of Carbon in Growing Fish: An Experimental Study of Isotopic Routing
}

\author{
Leona J. Kelly \\ Carlos Martínez del Rio* \\ Department of Zoology and Physiology, University of \\ Wyoming, Laramie, Wyoming 82071-3166
}

Accepted 11/2/2009; Electronically Published 3/4/2010

\begin{abstract}
The application of stable isotope analysis to ecology requires estimating the contribution of different isotopic sources to the isotopic signatures of an animal's tissues using mixing models. These models make the physiologically unrealistic assumption that assimilated nutrients are disassembled into their elemental components and that these atoms are then reassembled into biomolecules. We quantified the extent to which mixing models yield erroneous results with an experiment using Nile tilapia (Oreochromis niloticus). The tilapia were fed synthetic diets that varied in protein content and in which the carbon isotopic composition of protein differed widely from that of carbohydrates and lipids. We predicted that dietary protein would contribute disproportionately to the carbon in muscle, whereas the nonprotein components of diet would contribute disproportionately to lipids. Our experiment also allowed us to test the conjecture of a positive correlation between the ${ }^{15} \mathrm{~N}$ enrichment in tissues and protein intake. As predicted, the contribution of protein carbon to muscle was higher than that expected by the assumptions of isotopic mixing in all treatments except that with the lowest dietary protein content. We hypothesized that the unexpectedly high contribution of nonprotein carbon to muscle was the result of assimilating both dispensable and indispensable amino acids synthesized by the fishes' gut microbiota. Although we expected the contribution of carbon in nonprotein dietary ingredients to be higher than expected from a mixing model, we found that protein contributed more than expected, probably as a result of differences in amino acid composition between diet and tissues, which led to excess carbon used for lipid synthesis. Finally, our results verified the positive relationship between dietary protein content and the enrichment in tissue ${ }^{15} \mathrm{~N}$. Assuming perfect mixing in field isotopic studies can lead to erroneous inferences about the relative contributions of different sources to an animal's diet.
\end{abstract}

*Corresponding author; e-mail: cmdelrio@uwyo.edu.

Physiological and Biochemical Zoology 83(3):473-480. 2010. (C) 2010 by The University of Chicago. All rights reserved. 1522-2152/2010/8303-9018\$15.00 DOI: $10.1086 / 649628$

\section{Introduction}

Many ecological applications of stable isotope analyses require estimating the contribution of different isotopic sources to the tissues of an animal using mixing models. In a mixing model, the fractional contribution of an isotopic source to a tissue is estimated from the isotopic composition of the tissue and from the isotopic composition of the dietary sources. The simplest mixing model is

$$
\delta_{\mathrm{T}}=f_{\mathrm{A}} \delta_{\mathrm{A}}+f_{\mathrm{B}} \delta_{\mathrm{B}}
$$

where $\delta_{\mathrm{T}}$ is the isotopic composition of an animal's tissue, $\delta_{\mathrm{A}}$ and $\delta_{\mathrm{B}}$ are the isotopic compositions of sources $\mathrm{A}$ and $\mathrm{B}$, and $f_{\mathrm{A}}$ and $f_{\mathrm{B}}$ are their relative fractional contributions $\left(f_{\mathrm{B}}=1-\right.$ $f_{\mathrm{A}}$; Phillips 2001). Using Equation (1) (or for its more complex elaborations, see Phillips and Gregg 2001, 2003; Phillips and Koch 2002; Martínez del Rio and Wolf 2005) assumes (1) that the elemental composition (i.e., the $\mathrm{C}: \mathrm{N}$ ratio) of all the diets is equal, (2) that the efficiency with which each element in each source is assimilated is the same, (3) that there is no tissue-todiet discrimination (i.e., $\Delta X=\delta X_{\text {tissues }}-\delta X_{\text {source }}=0$, where $X$ is an element), and (4) that there is no isotopic routing. The variation among sources in elemental ratios and in assimilation efficiency can be addressed with concentration-dependent mixing models (Phillips and Koch 2002) and by adding an assimilation efficiency term to the models (Martínez del Rio and Wolf 2005). Discrimination factors for each source $\left(\Delta_{\mathrm{A}}\right.$ and $\left.\Delta_{\mathrm{B}}\right)$ can be measured experimentally and included in the mixing model (reviewed in Martínez del Rio et al. 2009). The isotopic routing assumption has received much less attention (Ambrose and Norr 1993; Podlesak and McWilliams 2006).

What does this assumption entail? Mixing models assume that assimilated nutrients are disassembled into their elemental components and that these atoms are then reassembled into the molecules that make up tissues (Martínez del Rio et al. 2009). Van der Merwe (1982) called this unrealistic assumption the "scrambled egg" premise. To illustrate why the scrambled egg assumption is unrealistic, consider carbon. The building blocks that animals use to manufacture the biomolecules in tissues are not carbon atoms but the carbon skeletons of many molecules (Horton et al. 2002). Depending on the type of biomolecule, these carbon skeletons are conserved to various degrees from assimilation to the manufacture and breakdown of macromolecules (Horton et al. 2002). For example, the amino acid pool in an animal's tissues comprises indispensable amino 
acids whose carbon skeletons are derived from diet, as well as dispensable amino acids whose carbon skeletons come from either diet or are endogenously manufactured from other macromolecules (Bequette 2003). All animals violate the "no isotopic routing" assumption to a greater or lesser degree. The question is whether violating this assumption leads to wrong inferences when mixing models are used.

Available evidence indicates that isotopic routing can pose significant problems to interpreting mixing models. Voigt et al. (2008), for example, found that the isotopic composition of carbon dioxide in the breath of fruit-eating bats reflected the $\delta^{13} \mathrm{C}$ values of the plant component of the bat's diet, whereas the isotopic composition of wing tissue reflected that of the insect component. In a similar fashion, Podlesak and McWilliams (2006) fed yellow-rumped warblers semisynthetic diets in which the $\delta^{13} \mathrm{C}$ value of the protein component of the diet differed from that of the carbohydrate and lipid components. They found that the contribution of carbon from the protein component of the diet was much higher in the bird's blood cells than expected from mixing models. Consequently, when the $\delta^{13} \mathrm{C}$ values of blood cells were used in mixing models, they greatly overestimated the contribution of protein to the birds' diet (Martínez del Rio et al. 2009). Although isotopic routing has been recognized as an interesting, and problematic, phenomenon for a long time (reviewed in Ambrose and Norr 1993; Martínez del Rio et al. 2009), it has received relatively scant recent attention.

We used Nile tilapia (Oreochromis niloticus), an omnivorous fish, to examine the potential complications that isotopic routing poses to applying mixing models. Briefly, we fed tilapia one of four diets that varied in protein content and in which the carbon isotopic composition of protein $(-27.0 \% \pm \pm 0.1 \%$ o differed from that of carbohydrate $(-11 \%$ o $\pm 0.01 \%$ o $)$. We predicted that, for all diets, the $\delta^{13} \mathrm{C}$ values of muscle protein would differ from the values predicted by a concentration-dependent mixing model and that the observed values would be more similar to the $\delta^{13} \mathrm{C}$ values of dietary protein. This prediction stemmed from the observation that a large fraction of all carbon in muscle protein (Santiago and Lovell 1988; Reeds 2000) is contained in essential amino acids, which, by definition, must be obtained from dietary protein (Reeds 2000). Thus, even when fish are fed on the diets with the lowest protein content, the carbon in their tissues should be imprinted with a strong carbon isotopic signal from dietary protein. We also predicted that the isotopic composition of lipids would differ from the $\delta^{13} \mathrm{C}$ values predicted by a concentration-dependent mixing model and that their $\delta^{13} \mathrm{C}$ values would reflect the carbon isotopic composition of dietary carbohydrates and lipids. We expected lipids to be built primarily from carbon derived from nonprotein sources for low-protein diets when protein is presumably in short supply and should be allocated primarily to growth (see Martínez del Rio et al. 2009). In summary, we predicted that the isotopic composition of tissue protein would reflect that of dietary protein, whereas the isotopic composition of tissue lipids would reflect that of dietary carbohydrates and lipids (see Ambrose and Norr 1993).
Although our experiments had isotopic routing as a primary focus, their design allowed us to also examine the effect of protein intake on the discrimination factor of ${ }^{15} \mathrm{~N}$ between tissues and $\operatorname{diet}\left(\Delta^{15} \mathrm{~N}=\delta^{15} N_{\text {tissues }}-\delta^{15} \mathrm{~N}_{\text {diet }}\right)$. Because ${ }^{15} \mathrm{~N}$ biomagnifies along trophic chains (Martínez del Rio et al. 2009), ecologists often use $\delta^{15} \mathrm{~N}$ to diagnose trophic level (Post 2002). Because the magnitude of $\Delta^{15} \mathrm{~N}$ determines the degree of ${ }^{15} \mathrm{~N}$ biomagnification at each trophic step, finding out the factors that determine its value has ecological implications. One factor hypothesized to influence the value of $\Delta^{15} \mathrm{~N}$ is dietary protein content. Briefly, nitrogenous waste products, such as ammonia, urea, and uric acid, tend to be depleted in ${ }^{15} \mathrm{~N}$ relative to tissues (reviewed in Tibbets et al. 2007; Tsahar et al. 2007). Thus, because animals feeding on diets with higher protein content excrete a higher fraction of ${ }^{15} \mathrm{~N}$-depleted nitrogenous products, their tissues must become relatively enriched in ${ }^{15} \mathrm{~N}$. Because the studies that have aimed to examine it have not varied protein quality independently of protein quantity, this prediction has not been adequately tested (reviewed in Martínez del Rio et al. 2009). Our experiment varied protein content without varying its quality and therefore provided an opportunity to test whether $\Delta^{15} \mathrm{~N}$ increases with dietary protein content when protein quality remains constant.

\section{Material and Methods}

\section{Tilapia Maintenance and Experimental Design}

Eighty fingerling tilapia were purchased in June 2007 (AmeriCulture, Animas, NM) and were housed in the University of Wyoming's Red Buttes Animal Care Facility. Eighty fish (average initial mass $\pm \mathrm{SD}=0.51 \pm 0.07 \mathrm{~g}$ ) were randomly assigned to one of four different experimental groups and placed individually in tanks $(10$ inches $\times 10$ inches $\times 6$ inches) at $24^{\circ} \mathrm{C}\left( \pm 1^{\circ} \mathrm{C}\right)$ and a $12 \mathrm{~L}: 12 \mathrm{D}$ photoperiod. The throughput rate of the holding tanks was $80-90 \mathrm{~mL} / \mathrm{d}$. The four experimental groups were fed diets that varied in $(a)$ relative protein content (Table 1$)$ and $(b)$ isotopic composition (Table 2). Fish were fed once daily at a ration that exceeded their maximal intake.

Table 1: Chemical composition (\%) of experimental diets

\begin{tabular}{lrrrr}
\hline & Diet 1 & Diet 2 & Diet 3 & Diet 4 \\
\hline Casein & 3.75 & 7.50 & 15.00 & 30.00 \\
Corn starch & 56.25 & 52.50 & 45.00 & 30.00 \\
Corn syrup & 20.00 & 20.00 & 20.00 & 20.00 \\
Corn oil & 10.00 & 10.00 & 10.00 & 10.00 \\
Cellulose & 5.50 & 5.50 & 5.50 & 5.50 \\
Methyl cellulose & 1.50 & 1.50 & 1.50 & 1.50 \\
Dicalcium phosphate & 1.50 & 1.50 & 1.50 & 1.50 \\
Vitamin mix & 1.50 & 1.50 & 1.50 & 1.50 \\
Mineral mix & .18 & .18 & .18 & .18 \\
\hline
\end{tabular}

${ }^{a}$ Manganese $(25 \mathrm{mg} / \mathrm{kg})$, zinc $(100 \mathrm{mg} / \mathrm{kg})$, iron $(44 \mathrm{mg} / \mathrm{kg})$, copper (3 $\mathrm{mg} / \mathrm{kg})$, iodine $(5 \mathrm{mg} / \mathrm{kg})$, cobalt $(0.05 \mathrm{mg} / \mathrm{kg})$, selenium $(0.3 \mathrm{mg} / \mathrm{kg})$. 
Table 2: Elemental and isotopic composition of ingredients of experimental diets

\begin{tabular}{lcccc}
\hline & $\% \mathrm{C} \pm \mathrm{SD}$ & $\% \mathrm{~N} \pm \mathrm{SD}$ & $\delta^{13} \mathrm{C}(\% 0) \pm \mathrm{SD}$ & $\delta^{15} \mathrm{~N}(\% 0) \pm \mathrm{SD}$ \\
\hline Casein & $48.5 \pm 2.9$ & $13.3 \pm .8$ & $-27.0 \pm .10$ & $7.1 \pm .1$ \\
Corn starch & $41.1 \pm .1$ & $\ldots$ & $-11.0 \pm .01$ & $\ldots$ \\
Corn syrup & $31.4 \pm 1.6$ & $\ldots$ & $-11.0 \pm .04$ & $\ldots$ \\
Corn oil & $70.1 \pm 2.0$ & $\ldots$ & $-13.2 \pm .02$ & $\ldots$ \\
Cellulose & $43.0 \pm .6$ & $\ldots$ & $-11.0 \pm .02$ & $\ldots$ \\
Methyl cellulose & $50.0 \pm 2.2$ & $\ldots$ & $-11.0 \pm .03$ & $\ldots$ \\
Casein: & & & & \\
$\quad 3.75 \%$ & $46.9 \pm 1.3$ & $1.1 \pm .1$ & $-13.4 \pm .1$ & $7.1 \pm .3$ \\
$\quad 7.7 \%$ & $50.5 \pm 4.6$ & $1.7 \pm .5$ & $-14.1 \pm .4$ & $7.1 \pm .5$ \\
$\quad 15 \%$ & $50.0 \pm 3.9$ & $2.7 \pm .3$ & $-15.4 \pm .3$ & $7.1 \pm .2$ \\
$\quad 30 \%$ & $47.0 \pm 2.2$ & $4.4 \pm .1$ & $-18.0 \pm .2$ & $7.1 \pm .12$ \\
\hline
\end{tabular}

\section{Sample Collection and Stable Isotope Analysis}

We used $\mathrm{CO}_{2}$ asphyxiation (American Veterinary Medical Association 2007) to kill five fish per treatment, chosen at random, when the average mass of all fish in the treatment was $\approx 150 \%$, $200 \%, 250 \%$, and $300 \%$ of starting mass. Because growth rate differed among fish, the time at which each fish was killed varied between 28 and $133 \mathrm{~d}$. Our protocol was approved by the University of Wyoming's International Animal Care and Use Committee (A-3216-01). Killed fish were immediately stored frozen at $-20^{\circ} \mathrm{C}$. We dissected lateral myotome muscles from each fish and dried them to constant mass at $40^{\circ} \mathrm{C}$. Dried muscle tissue was ground into a homogenous mixture. Lipid was then extracted from the mixture with three sequential petroleum ether extractions. The solvent was evaporated to recover the extracted residue (which we shall refer to as lipid). Lean tissue and lipid samples were loaded into $3 \times 5-\mathrm{mm}$ tin capsules $\left(0.80 \pm 0.03 \mathrm{mg}\right.$ for $\delta^{13} \mathrm{C}$ and $\delta^{15} \mathrm{~N}$ analyses, and $0.05-$ $0.20 \mathrm{mg}$ for $\delta^{13} \mathrm{C}$ only analyses). Samples were analyzed for ${ }^{13} \mathrm{C} /$ ${ }^{12} \mathrm{C}$ with a Finnigan Delta Plus XP continuous flow stable isotope ratio mass spectrometer online, with a Costech EA 4010 element analyzer, at the University of Wyoming's Light Stable Isotope Facility. Isotopic ratios in this article are reported on a per mill (\%o) basis. Standards for these samples were vacuum oil $\left(\delta^{13} \mathrm{C}=-27.5 \%\right.$, $\left.\mathrm{VPDB}\right)$ and $\mathrm{ANU}$ sucrose $\left(\delta^{13} \mathrm{C}=-10.5 \%\right.$, VPDB, NIST 8542) for $\delta^{13} \mathrm{C}$ and peptone $\left(\delta^{15} \mathrm{~N}=5.6 \%\right.$, AIR, USG40 8542) and glycine $\left(\delta^{1} 5 \mathrm{~N}=\right.$ $0.73 \%$, AIR, IAEAN2) for $\delta^{15} \mathrm{~N}$. We included standards in every run to correct raw values obtained from the mass spectrometer.

\section{Statistical Analyses}

Because fish were at the exponential phase of growth, we estimated growth rate as $\left[\ln \left(w_{\mathrm{f}} / w_{0}\right)\right] /$ time, where $w_{\mathrm{f}}$ is the mass at the time of euthanasia and $w_{0}$ is the initial mass (Ebert 1999). We compared the effect of protein content on growth rate and lipid content of muscle with one-way ANOVA followed by Tukey-Kramer HSD (honestly significant difference). In animals such as tilapia, with relatively low isotopic incorporation rates, the isotopic composition of tissues is the mass-weighted average of tissue present before a diet shift and newly incor- porated tissue. We estimated the carbon isotopic composition of newly incorporated tissue $\left(\delta_{\mathrm{i}}\right)$ with a linear mixing model as

$$
\delta_{\mathrm{T}}=\frac{w_{0}}{w_{\mathrm{f}}} \delta_{0}+\frac{\Delta w}{w_{\mathrm{f}}} \delta_{\mathrm{i}}
$$

where and $\delta_{0}$ and $\delta_{\mathrm{T}}$ values equal the initial and final isotopic composition and $\Delta w=w_{\mathrm{f}}-w_{0}$. The terms $w_{0} / w_{\mathrm{f}}$ and $\Delta w / w_{\mathrm{f}}$ represent the fractional contributions of the initial and the newly incorporated tissue, respectively. Equation (2) can be rearranged to yield

$$
\delta_{\mathrm{T}}=\delta_{0}+\frac{\Delta w}{w_{\mathrm{f}}}\left(\delta_{\mathrm{i}}-\delta_{0}\right) .
$$

Thus, $\delta_{\mathrm{T}}$ is linearly related with $\Delta w / w_{\mathrm{f}}$. The value of $\delta_{\mathrm{i}}$ can be estimated by extrapolation as the value of $\delta_{\mathrm{T}}$ when $\Delta w / w_{\mathrm{f}}=$ 1 (i.e., when the value of $w_{\mathrm{f}}$ is large relative to $w_{0}$ ). A $95 \%$ confidence interval for $\delta_{i}$ can be estimated from the standard error of a predicted value as

$$
t_{0.05(2), n-2}\left(s_{Y \cdot X}^{2}\left[\frac{1}{n}+\frac{(1-\bar{X})^{2}}{\sum x^{2}}\right]\right),
$$

where $s_{Y \cdot X}^{2}$ is the residual mean square error (Zar 1996, p. 333).

This mixing model makes three crucial assumptions: (1) It assumes that the change in the isotopic composition of the tissues of experimental fish was the result of growth rather than catabolic turnover (Hesslein et al. 1993). This seems to be the case in the majority of rapidly growing ectotherms (reviewed in Martínez del Rio et al. 2009). (2) It assumes that we can estimate the growth of each tissue by the growth of the whole body and hence that the mass of each tissue scales isometrically with body mass. That is, the model assumes that the contribution of different tissues (muscle and lipids in muscle in this study) to body mass does not change as fish grow and that there are no differences among treatments (i.e., protein content in diet) in tissue composition. To test this assumption, we used multiple regression to assess the effect of treatment and time 

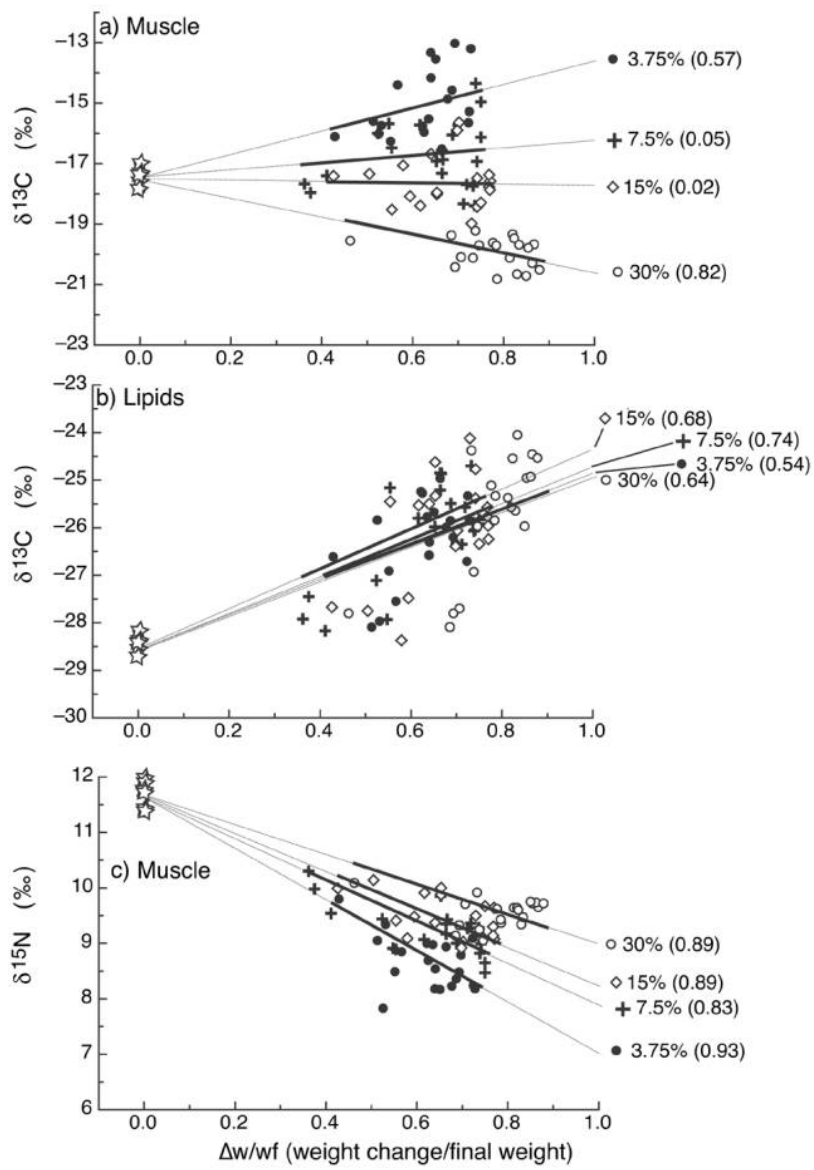

Figure 1. The isotopic composition of fish tissues changes as fish grow. The relationship between the isotopic composition of tissues and the relative change in weight $\left(\Delta w / w_{\mathrm{f}}=\right.$ weight change/final weight $)$ allows for estimating the isotopic composition of newly deposited tissue as the isotopic value of the tissue when $\Delta w / w_{\mathrm{f}}=1$. The $r^{2}$ values are in parentheses.

on the percentage of lipid in muscle. (3) Finally, our model assumes that the isotopic composition of incorporated tissue does not change as animals grow. This assumption is likely to be satisfied in fish growing exponentially (see "Results") but is not likely to be satisfied by all growing animals. For example, it is likely that the allocation of different diet components changes after animals reach their asymptotic mass and less protein is required for growth. We used $r^{2}$ to assess the fit of Equation (2) to data.

The $\delta^{13} \mathrm{C}$ value of diet was similar to the estimation using a concentration-dependent mixing model from each diet's elemental and isotopic composition. We tested the positive correlation between $\Delta^{15} \mathrm{~N}_{\text {tissues-diet }}$ and protein content in diet with a one-tailed Spearman rank coefficient of correlation.

\section{Results}

Protein content of diet had a significant effect on growth rate $\left(F_{3,76}=7.3, P<0.0002\right)$. The growth rate of fish that consumed the diet with the highest protein content (30\%, average growth rate $\pm \mathrm{SD}=0.03 \pm 0.01 \mathrm{~d}^{-1}$ ) was significantly higher than the growth rate of the fish that consumed the diets with lower protein contents $(3.75 \%, 7.5 \%$, and $15 \%$, average growth rate $\left.\pm \mathrm{SD}=0.02 \pm 0.01 \mathrm{~d}^{-1}\right)$, which did not differ from each other (Tukey's HSD). Muscle lipid content (mean \pm $\mathrm{SD}=8.5 \% \pm 5.2 \%)$ did not differ significantly among treatments $\left(F_{3,74}=1.12, P=0.35\right)$ or with time $\left(F_{1,74}=0.97\right.$, $P=0.33)$.

Figure 1 graphically depicts the method we used to estimate the carbon isotopic composition of deposited muscle (Fig. 1a) and lipid (Fig. 1b), as well as the nitrogen isotopic composition of deposited muscle (Fig. 1c). As predicted, the $\delta^{13} \mathrm{C}$ values of carbon deposited in muscle were more negative than those of diet at all but the lowest dietary protein contents (Figs. 1a, 2; Table 3). Contrary to our predictions, however, the isotopic composition of lipid was significantly more depleted in ${ }^{13} \mathrm{C}$ than in diet (Figs. 1a, 2; Table 3). Nitrogen's tissue-to-diet discrimination $\left(\Delta^{15} \mathrm{~N}_{\text {tissue-diet }}\right)$ increased significantly with dietary protein content (Spearman rank $r=1, P<0.05, N=4$; Fig. 3).

\section{Discussion}

Our results documented clear isotopic routing in tilapia. As predicted, the contribution of protein carbon to muscle was higher than expected by the assumptions of isotopic mixing in all treatments, except that with the lowest dietary protein content. Although we expected the contribution of carbon in nonprotein dietary ingredients to be higher than expected by a mixing model, we found the opposite. Protein appeared to contribute more to lipid carbon than we had expected. Finally, our results verified the positive relationship between dietary protein content and the ${ }^{15} \mathrm{~N}$ tissue-to-diet discrimination factor. Our results hinged on a novel mass-balance method of estimating the isotopic composition of deposited tissues. This discussion considers questions in three broad areas: (1) How much can we trust our estimation procedure? (2) What are the mechanisms that explain our results? (3) What are the implications

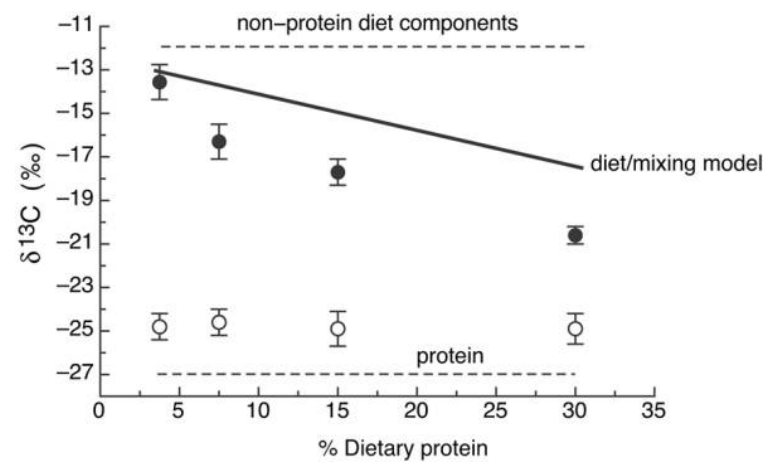

Figure 2. With the exception of fish fed on the diet with the lowest protein content, the $\delta^{13} \mathrm{C}$ of fish lean muscle (filled circles) was more negative than expected from using a mixing model (heavy line). The $\delta^{13} \mathrm{C}$ of extracted lipid (open circles) was also more negative than expected from perfect mixing. Bars are 95\% confidence intervals. These results suggest routing of carbon from dietary protein into both muscle and extracted lipids. 
Table 3: Estimated values of $\delta^{13} \mathrm{C}$ in muscle and extracted lipid, and $\delta^{15} \mathrm{~N}$ in muscle in Nile tilapia fed diets that varied in protein (casein) content and in which casein had a different $\delta^{13} \mathrm{C}$ than the nonprotein components of diet

\begin{tabular}{lrrrr}
\hline \multicolumn{5}{l}{ Protein Content } \\
\cline { 2 - 5 } & \multicolumn{1}{l}{$3.75 \%$} & \multicolumn{1}{l}{$7.5 \%$} & $15 \%$ & \multicolumn{1}{c}{$30 \%$} \\
\hline Muscle $\delta^{13} \mathrm{C} \pm 95 \% \mathrm{CI}(\% \mathrm{o})$ & $-13.6 \pm .8$ & $-16.3 \pm .8$ & $-17.7 \pm .6$ & $-20.6 \pm .4$ \\
Lipid $\delta^{13} \mathrm{C} \pm 95 \% \mathrm{CI}(\%)$ & $-24.8 \pm .6$ & $-24.6 \pm .6$ & $-24.9 \pm .8$ & $-24.9 \pm .7$ \\
Muscle $\delta^{15} \mathrm{~N} \pm 95 \%$ CI $(\% 0)$ & $6.9 \pm .4$ & $8.0 \pm .3$ & $8.4 \pm .3$ & $9.0 \pm .4$ \\
\hline
\end{tabular}

Note. $\mathrm{CI}=$ confidence interval.

of isotopic routing for the application of stable isotopes to field studies?

\section{How Trustworthy Are Our Estimates of $\delta_{i}$ ?}

The method that we have described to estimate $\delta_{i}$, the isotopic composition of deposited tissue, is independent of the form of the mathematical function that describes fish growth but hinges on the pivotal assumption that growth rate is the primary determinant of isotopic incorporation. We believe that this assumption was satisfied, as tilapia were fed ad lib. and were growing rapidly (Winfree and Stickney 1981). Because in many ectotherms growth rate is the primary determinant of isotopic incorporation rate, the method may be widely applied (Martinez del Rio et al. 2009). If fish are not growing exponentially, the assumptions listed in the introduction might not be satisfied and the use of the model is risky. The values of $r^{2}$ in Figure $1 a$ might suggest that Equation (2) fits the data poorly when fish are fed diets with $7.5 \%$ and $15 \%$ protein. However, $r^{2}$ should be interpreted as a comparison of the fit of the linear model relative to the mean (Anderson-Sprecher 1994). Thus, if $\delta_{\mathrm{i}} \approx$ $\delta_{\mathrm{T}}$, we should expect a slope of $\approx 0$ for Equation (2) and hence a low $r^{2}$ value.

\section{Isotopic Routing in Muscle, Potential Mechanisms}

Dietary protein carbon contributed to carbon muscle more than expected by the assumptions of isotopic mixing in all diets, except that with the lowest dietary protein content. Although we found evidence for significant carbon routing, its effects were detectable only at relatively high protein intakes. This result is unexpected because in tilapia muscle $\approx 50 \%$ of all carbon in protein is found in indispensable amino acids (Santiago and Lovell 1988). Thus, the expected $\delta^{13} \mathrm{C}$ should be more negative than that observed in all diets. Assuming that $\approx 50 \%$ of the carbon in muscle comes from essential amino acids derived from dietary protein yields a $\delta^{13} \mathrm{C}$ value equal to $-19.75 \%$. Thus, the contribution of essential amino acids should not only make the value of $\delta^{13} \mathrm{C}$ more negative than that expected from mixing but also make it more negative than the values observed at all but the highest levels of dietary protein (Fig. 2). This result indicates that a large fraction of the carbon in essential amino acids in fish fed diets containing less than $30 \%$ protein was derived from the carbohydrates and lipids in the diet. How does this nonprotein carbon make its way into putatively essential nutrients?

In mammals, indispensable amino acid requirements are met by diet, as well as by gastrointestinal tract microflora that contribute a significant fraction of some essential amino acids (Metges 2000). To our knowledge, the contribution of gut microbes to amino acid balance has not been studied in tilapia. However, there is evidence for the presence of significant fermentative activity in these fishes' gastrointestinal tracts (Kihara and Sakata 2002; Leenhouwers et al. 2008). We hypothesized that the tilapia's gut microbes contribute to the fishes' amino acid economy by manufacturing essential amino acids from carbon derived from dietary carbohydrates and lipids. Our results suggested that the relative contribution of microflora to the essential amino acid balance of tilapia is high when fish are fed diets with low protein content and decreases as protein content increases.

The term "protein sparing" is used in aquaculture to denote the ability of fish to maintain rapid growth rate when carbohydrates and lipids are substituted for protein in feeds (Shiau and Peng 1993; De Silva and Anderson 1994). The common explanation for protein sparing is that energy from carbohydrates and lipids "spares" amino acids from catabolic energyproviding processes and conserves them from growth (reviewed in Stone 2003). Our results suggest a complementary explanation. With the aid of their gut microbiota, tilapia seem to

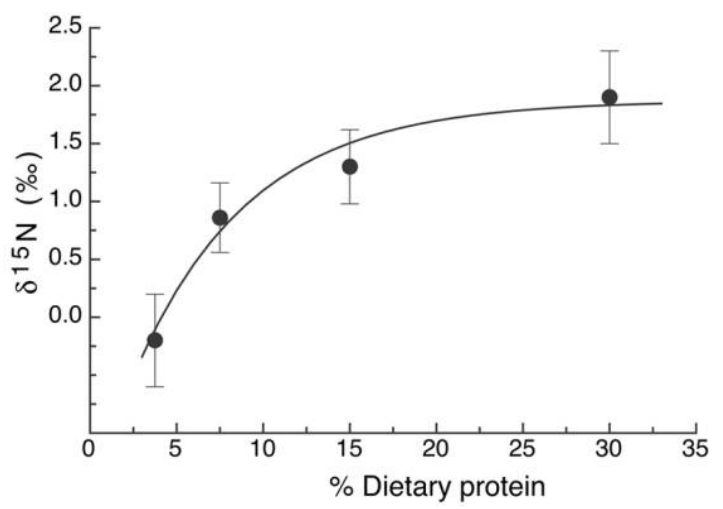

Figure 3. The difference between the $\delta^{15} \mathrm{~N}$ of muscle and $\operatorname{diet}\left(\Delta^{15} \mathrm{~N}\right)$ increased significantly with the protein content of diet (one-tailed Spearman rank $r=1, P<0.05)$. The curve equals $y=1.9-$ $3.5 \exp (-0.15 x)$ and was fitted for descriptive purposes only. 
be able to use the carbon skeletons of nonprotein diet components to manufacture both dispensable and indispensable amino acids. This conjecture, which has significant applied implications, can be tested by compound-specific isotopic analysis (Evershed et al. 2007). We predict that, in tilapia fed on proteindeficient diets, the carbon skeletons of both dispensable and indispensable amino acids will bear the isotopic imprint of the diet's nonprotein components.

\section{Routing of Dietary Protein Carbon into Muscle Lipids}

Contrary to our expectations, muscle lipids bore a signature that was more similar to that of dietary protein than to nonprotein dietary components (Fig. 2), and the $\delta^{13} \mathrm{C}$ value was very similar at all levels of protein intake (Table 3 ). These results imply that a significant fraction (more than 50\%; see "Implications for Dietary Reconstruction") of the carbon in lipids extracted from muscle was derived from dietary protein. This result is surprising for two reasons. (1) We expected protein to be spared for growth, especially when diet contains little protein (see Martínez del Rio et al. 2009). (2) It is presumed that the composition of muscle fatty acids in fish is strongly influenced by the fatty acid composition of dietary lipids (Huang et al. 1998; $\mathrm{Ng}$ et al. 2003). This assumption requires direct routing of dietary fatty acids into the lipid constituents of tissues. How can we explain the seemingly high contribution of dietary protein carbon to lipids? One possible explanation is the disparity in amino acid composition between casein and tilapia tissues (Priya Chemicals, http://www.priyachem.com/ casesoy.htm, 2006; Santiago and Lovell 1988), which leads to the deamination of amino acids present in relative excess (threonine, valine, leucine, and isoleucine; Santiago and Lovell 1988). The carbon skeletons of these amino acids are either catabolized or used to synthesize storage lipids. The contribution of protein to the carbon in lipids, and hence the magnitude of isotopic routing, likely depends on the match in amino acid composition between the animal's tissues and the dietary protein source, that is, the protein's biological value (Rao et al. 1964). We hypothesize a negative correlation between routing dietary protein carbon to lipids and the protein's biological value.

\section{Increased Protein Intake Leads to Increased $\Delta^{15} \mathrm{~N}$ in Tilapia}

DeNiro and Epstein (1981) noted that animal tissues were enriched in ${ }^{15} \mathrm{~N}$ relative to their diets (i.e., $\Delta^{15} \mathrm{~N}=\delta^{15} N_{\text {tissues }}-$ $\delta^{15} N_{\text {diet }}>0$ ) and led to the well-supported conjecture that the content of ${ }^{15} \mathrm{~N}$ in animal tissues is biomagnified along the length of a food chain (Post 2002). Because this conjecture allows ecologists to use $\delta^{15} \mathrm{~N}$ to estimate an animal's trophic level, it is important to find out the factors that determine the value of $\Delta^{15} \mathrm{~N}$. Among the factors that have been invoked to explain variation in the magnitude of $\Delta^{15} \mathrm{~N}$ are protein quality, protein use efficiency, and protein intake (reviewed in Martínez del Rio et al. 2009). Martínez del Rio and Wolf (2005) predicted that $\Delta^{15} \mathrm{~N}$ should increase with diet's protein content. This predic- tion has received mixed support: Pearson et al. (2003) found a positive relationship between $\Delta^{15} \mathrm{~N}_{\text {body-diet }}$ in yellow-rumped warblers (Dendroica coronata), and Focken (2001) found an increase in $\Delta^{15} \mathrm{~N}_{\text {body-diet }}$ with increased protein intake in tilapia. In contrast, Tsahar et al. (2007) found decreased $\Delta^{15} \mathrm{~N}$ in fruiteating birds fed diets with higher protein content, and Robbins et al. (2005) found no effect of protein content in a comparative study. Our experiment varied protein content without varying its quality and therefore provided a clear test for the putative positive relationship between $\Delta^{15} \mathrm{~N}$ and dietary protein content when protein quality remains constant. Although our small sample size prevented us from using inferential statistics, our results provide support for this positive relationship. Although our sample sizes are small, and the range of protein contents in diet is narrow, our results suggest a concave, decelerating relationship between $\Delta^{15} \mathrm{~N}$ and protein content (Fig. 3). The generality of these results awaits further experimental work.

\section{Differences between Ectotherms and Endotherms}

Our results are the first evidence of carbon isotopic routing in an ectotherm and are consistent with the results of Ambrose and Norr (1993) and Podlesak and McWilliams (2006) in two species of endotherms. Protein routing occurred in lean muscle tissue in laboratory mice (Mus musculus; Ambrose and Norr 1993) and yellow-rumped warblers (Dendroica coronata; Podlesak and McWilliams 2006). A notable difference between our results and Ambrose and Norr's (1993) and Podlesak and McWilliams's (2006) was the degree of isotopic routing between the fish and the endotherms. For example, Podlesak and McWilliams (2006) found that more than 30\% of the carbon in the plasma proteins of yellow-rumped warblers was derived from dietary protein. This value is much higher than the contribution of dietary protein carbon to muscle carbon in tilapia (Fig. 1; next paragraph). Klaassen and Nolet (2008) speculated that the cost of a high body temperature allows endotherms to use diets with higher $\mathrm{C}: \mathrm{N}$ (protein : nonprotein) ratios than ectotherms and to be more efficient in their use of protein for growth. Briefly, in herbivorous and omnivorous endotherms, the carbon-rich but nitrogen-poor nonprotein components of diet are used to fuel a high metabolic rate (Klaassen and Nolet 2008). We hypothesized that both the prevalence and the magnitude of isotopic routing will be higher in endotherms than in ectotherms.

\section{Implications for Dietary Reconstruction}

Because isotopic analyses are often used to reconstruct diet in fish (McCutchan et al. 2003), it is appropriate to ask the height of the magnitude of error that can be incurred when using a mixing model for an omnivorous fish when routing takes place. To answer this question, we compared the percentage of contribution of protein to muscle carbon, estimated by the mixing model, with the value in diet, which the mixing model attempts to reconstruct. We used the $\delta^{13} \mathrm{C}$ value of incorporated tissue from Table 3 as the input value in the mixing model. The mixing 


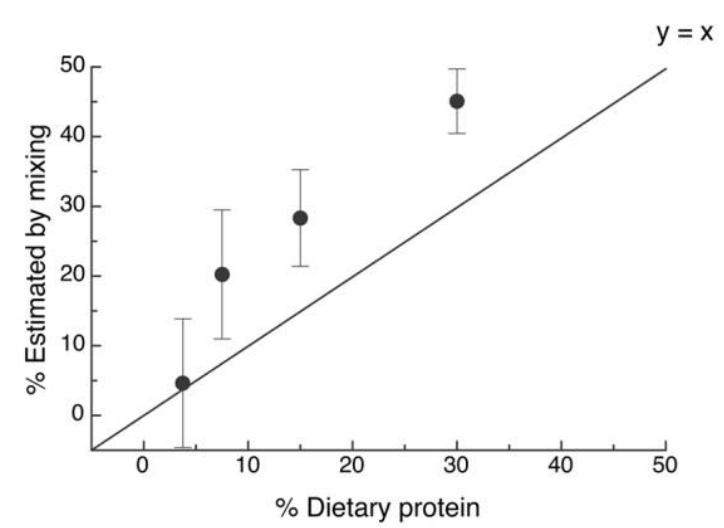

Figure 4. A mixing model overestimated the contribution of dietary protein to the overall diet at all, except the lowest, protein contents. Bars are $95 \%$ confidence intervals.

model consistently overestimated the contribution of dietary protein to overall diet in all treatments except that with the lowest dietary protein content (Fig. 4). The relative magnitude of overestimation was highest for the $7.5 \%$ diet, for which the mixing model estimated a contribution of dietary protein to total carbon intake that was 2.7 times higher than the protein content in diet (Fig. 4). Using the $\delta^{13} \mathrm{C}$ in lipids to reconstruct diet with a mixing model leads to the erroneous conclusior $\rightarrow$ that fish were ingesting roughly the same diet and that this diet contained from $68 \%$ to $69 \%$ protein. If one assumes a $-3 \%$ o fractionation in the synthesis of lipid from protein or carbohydrate (Post et al. 2007), the mixing model estimates that protein contributed from $50 \%$ to $53 \%$ to the overall diet. Usin the isotopic values of extracted lipids or muscle protein in mixing models would have led dramatically to different inferences about the fishes' diets. These results should give pause to ecologists aiming to use stable isotopes to reconstruct omnivorous diets.

Ecologists use various computer programs that apply isotopic data to reconstruct the relative contribution of different components of an animal's diet (reviewed in Martínez del Rio et al. 2009). Although the level of statistical and computational sophistication of these programs has increased steadily over the years (see Jackson et al. 2008), these programs assume perfect mixing and ignore isotopic routing's potential complications. Thus, their output for omnivores that ingest diets with com $\rightarrow$ ponents that differ dramatically in protein content is likely to be erroneous. These programs do not estimate the relative contribution of a given component to an animal's diet. They estimate the contribution of the component to the carbon/nitrogen content of the tissue's analyzed. Echoing the warning note that Gannes et al. (1998) made 10 yr ago, we urge caution in interpreting mixing models for animals that feed on both protein-rich animal and carbohydrate-rich plant materials ir $\rightarrow$ their diet. These animals include many omnivores, such as tilapia, as well as "nectar-feeders," "frugivores," and "granivores," which rely on plant materials for energy and animal prey for protein (Karasov and Martínez del Rio 2007; Voigt and Speakman 2007). With these animals, the results of mixing models likely overestimate the contribution of the high-protein content components to the animal's diet.

\section{Acknowledgments}

This work was supported by the National Science Foundation (IBN-0114016). Robert Carroll assisted in fish care, while Joe Bobbit and Steve Devries helped us build tanks and maintained water temperatures constant in the face of Wyoming's winter. This manuscript has benefited from the comments of Scott Carleton, Nathan Wolf, Seth Newsome, and three anonymous reviewers.

\section{Literature Cited}

Ambrose S.H. and L. Norr. 1993. Carbon isotopic evidence for routing of dietary protein to bone collagen, and whole diet to bone apatite carbonate: purified diet growth experiments. Pp. 1-37 in J. Lambert and G. Grupe, eds. Molecular Archeology of Prehistoric Human Bone. Springer, Berlin.

American Veterinary Medical Association (AVMA). 2007. Guidelines on euthanasia (formerly report of the AVMA Panel on Euthanasia), 2007:19-20.

Anderson-Sprecher R. 1994. $R^{2}$ and model comparisons. Am Stat 48:113-117.

Bequette B.J. 2003. Amino acid metabolism in animals: an overview. Pp. $87-101$ in J.P.F. D’Mello, ed. Amino Acids in Animal Nutrition. CABI, Wallingford.

$\rightarrow$ DeNiro M.J. and S. Epstein. 1981. Influence of diet on the distribution of nitrogen isotopes in animals. Geochim Cosmochim Acta 45:341-351.

De Silva S.S. and T.A. Anderson. 1995. Fish Nutrition in Aquaculture. Springer, New York.

Ebert T.A. 1998. Plant and Animal Populations: Methods in Demography. Academic Press, San Diego, CA.

Evershed R.P., I.D. Bull, L.T. Corr, Z.M. Crossman, B.E. Van Dongen, C. Evans, S. Jim, H. Mottram, A.J. Mukherjee, and R.D. Pancost. 2007. Compound-specific stable isotope analysis in ecological research. Pp. 480-540 in R. Michener and K. Lajtha, eds. Stable Isotopes in Ecology and Environmental Science. 2nd ed. Blackwell, London.

$\rightarrow$ Focken U. 2001. Stable isotopes in animal ecology: the effect of ration size on the trophic shift of $\mathrm{C}$ and $\mathrm{N}$ isotopes between feed and carcass. Isotopes Environ Health Stud 37: 199-211.

Gannes L.Z., C. Martínez del Rio, and R. Koch. 1998. Natural abundance variations in stable isotopes and their potential uses in animal physiological ecology. Comp Biochem Physiol 119A:725-737.

Hesslein R.H., K.A. Hallard, and P. Ramal. 1993. Replacement of sulfur, carbon, and nitrogen in tissue of growing broad whitefish (Coregonus nasus) in response to a change in diet traced by $\delta^{34} \mathrm{~S}, \delta^{13} \mathrm{C}$, and $\delta^{15} \mathrm{~N}$. Can J Fish Aquat Sci 50:20712076. 
Horton R.H., L.A. Moran, R.S. Ochs, D.J. Rawn, and K.G $\rightarrow$ Phillips D.L. and P.L. Koch. 2002. Incorporating concentration Scrimgeour. 2002. Principles of Biochemistry. Prentice Hall, Upper Saddle River, NJ. dependence in stable isotope mixing models. Oecologia 130: 114-125.

$\rightarrow$ Huang C.H., M.C. Huang, and P.C. Hou. 1998. Effect of dietar $\rightarrow$ Podlesak D.W. and S.R. McWilliams. 2006. Metabolic routing lipids on fatty acid composition and lipid peroxidation in sarcoplasmic reticulum of hybrid tilapia, Oreochromis niloticus $\times$ O. aureus. Comp Biochem Physiol 120:331-336.

$\rightarrow$ Jackson A.L., R. Inger, S. Bearhop, and A. Parnell. 2008. Er $\rightarrow$ roneous behavior of MixSIR, a recently published Bayesian isotope mixing model: a discussion of Moore and Semmens (2008). Ecol Lett 12:E1-E5.

Karasov W.H. and C. Martínez del Rio. 2007. Physiological Ecology: How Animals Process Energy, Nutrients, and Toxins. Princeton University Press, Princeton, NJ.

$\rightarrow$ Kihara M. and T. Sakata. 2002. Production of short-chain fatty acids and gas from various oligosaccharides by gut microbes of carp (Cyprinus carpio L.) in micro-scale batch culture. Comp Biochem Physiol 132:333-340.

$\rightarrow$ Klaassen M. and B.A. Nolet. 2008. Stoichiometry of endothermy: shifting the quest from nitrogen to carbon. Ecol Lett 11:785-792.

$\rightarrow$ Leenhouwers J.I., W.F. Pellikaan, H.F.A. Huizing, R.O.M. Coolen, J.A.J. Verreth, and J.W. Schrama. 2008. Fermentability of carbohydrates in an in vitro batch culture method using inocula from Nile tilapia (Oreochromis niloticus) and European sea bass (Dicentrarchus labrax). Aquacult Nutr $14 . \rightarrow$ 523-532.

Martínez del Rio C. and B.O. Wolf. 2005. Mass balance models for animal isotopic ecology. Pp. 141-174 in M.A. Starck anc $\rightarrow$ T. Wang, eds. Physiological and Ecological Adaptations to Feeding in Vertebrates. Science, Enfield, NH.

$\rightarrow$ Martínez del Rio C., N. Wolf, S. Carleton, and L.Z. Gannes. 2009. Isotopic ecology ten years after a call for more laboratory experiments. Biol Rev 84:91-111. of dietary nutrients in birds: effects of diet quality and macronutrient composition revealed using stable isotopes. Physiol Biochem Zool 79:534-549.

Post D.M. 2002. Using stable isotopes to estimate trophic position: models, methods, and assumptions. Ecology 83:703718.

$\rightarrow$ Post D.M., C.A. Layman, D.A. Arrington, G. Takimoto, J. Quattrochi, and C.G. Montaña. 2007. Getting to the fat of the matter: models, methods, and assumptions for dealing with lipids in stable isotope analysis. Oecologia 152:179-189.

Rao P.B.R., H.W. Norton, and B.C. Johnson. 1964. The amino acid composition and nutritive value of proteins. J Nutr 82: 88-92.

Reeds P.J. 2000. Dispensable and indispensable amino acids for humans. J Nutr 130:1835S-1840S.

$\rightarrow$ Robbins C.T., L.A. Felicetti, and M. Sponheimer. 2005. The effects dietary protein quality on nitrogen isotope discrimination in mammals and birds. Oecologia 144:534-540.

Santiago C.B. and R.T. Lovell. 1988. Amino acid requirements for growth of Nile tilapia. J Nutr 118:1540-1546.

$\rightarrow$ Shiau S.Y. and C.Y. Peng. 1993. Protein-sparing effect by carbohydrates in diets for tilapia, Oreochromis niloticus $\times O$. aureus. Aquaculture 117:327-334.

Stone D.A. 2003. Dietary carbohydrate utilization by fish. Rev Fish Sci 11:337-369.

Tibbets T., L.A. Wheeless, and C. Martínez del Rio. 2007. Isotopic enrichment without change in diet: an ontogenetic shift in $\delta^{15} \mathrm{~N}$ during insect metamorphosis. Funct Ecol 22:109113.

$\rightarrow$ McCutchan J.H., Jr., W.M. Lewis Jr., C. Kendall, and C.C $\rightarrow$ Tsahar E., N. Wolf, I. Ishaki, Z. Arad, and C. Martínez del Rio. McGrath. 2003. Variation in trophic shift for stable isotope ratios of carbon, nitrogen, and sulfur. Oikos 102:378-390.

Metges C.C. 2000. Contribution of microbial amino acids to amino acid homeostasis of the host. J Nutr 130:1857S-1863S.

$\rightarrow$ Ng W.K., P.K. Lim, and H. Sidek. 2001. The influence of a dietary lipid source on growth, muscle fatty acid composition, and erythrocyte osmotic fragility of hybrid tilapia. Fish Physiol Biochem 25:301-310.

$\rightarrow$ Pearson S.F., D.J. Levey, C.H. Greenberg, and C. Martínez del Rio. 2003. Effects of elemental composition on the incorporation of dietary nitrogen and carbon and isotopic signatures in an omnivorous songbird. Oecologia 135:516-523.

$\rightarrow$ Phillips D.L. 2001. Mixing models in analyses of diet using multiple stable isotopes: a critique. Oecologia 127:166-170.

$\rightarrow$ Phillips D.L. and J.W. Gregg. 2001. Uncertainty in source partitioning using stable isotopes. Oecologia 127:171-179.

$\rightarrow-$ 2003. Source partitioning using stable isotopes: coping with too many sources. Oecologia 136:261-269. 2007. Diet influences the rate of ${ }^{15} \mathrm{~N}$ incorporation in blood cells and plasma of yellow-vented bulbuls (Pycnonotus xanthopygos). J Exp Biol 211:459-465.

Van der Merwe N.J. 1982. Carbon isotopes, photosynthesis, and archaeology. Am Sci 70:596-605.

$\rightarrow$ Voigt C.C., K. Rex, R.H. Michener, and J.R. Speakman. 2008. Nutrient routing in omnivorous animals tracked by stable carbon isotopes in tissue and exhaled breath. Oecologia 157: 31-40.

Voigt C.C. and J.R. Speakman. 2007. Nectar-feeding bats fuel their high metabolism directly with exogenous carbohydrates. Funct Ecol 21:913-921.

Winfree R.A. and R.R. Stickney. 1981. Effects of dietary protein and energy on growth, feed conversion efficiency and body composition of Tilapia aurea. J Nutr 111:1001-1012.

Zar J.H. 1996. Biostatistical Analysis. 3rd ed. Prentice Hall, Upper Saddle River, NJ. 